\title{
Continuous negative extrathoracic pressure combined with high-frequency oscillation improves oxygenation with less impact on blood pressure than high-frequency oscillation alone in a rabbit model of surfactant depletion
} Sachie Naito, Takehiko Hiroma and Tomohiko Nakamura*

Address: Division of Neonatology, Nagano Children's Hospital, Nagano, Japan

Email: Sachie Naito - tnakamura@naganoch.gr.jp; Takehiko Hiroma - tnakamura@naganoch.gr.jp;

Tomohiko Nakamura* - tnakamura@naganoch.gr.jp

* Corresponding author

Published: 31 October 2007

BioMedical Engineering OnLine 2007, 6:40 doi:10.1 186/1475-925X-6-40
Received: 10 May 2007

Accepted: 3I October 2007

This article is available from: http://www.biomedical-engineering-online.com/content/6/1/40

(c) 2007 Naito et al; licensee BioMed Central Ltd.

This is an Open Access article distributed under the terms of the Creative Commons Attribution License (http://creativecommons.org/licenses/by/2.0), which permits unrestricted use, distribution, and reproduction in any medium, provided the original work is properly cited.

\begin{abstract}
Background: Negative air pressure ventilation has been used to maintain adequate functional residual capacity in patients with chronic muscular disease and to decrease transpulmonary pressure and improve cardiac output during right heart surgery. High-frequency oscillation (HFO) exerts beneficial effects on gas exchange in neonates with acute respiratory failure. We examined whether continuous negative extrathoracic pressure (CNEP) combined with HFO would be effective for treating acute respiratory failure in an animal model.
\end{abstract}

Methods: The effects of CNEP combined with HFO on pulmonary gas exchange and circulation were examined in a surfactant-depleted rabbit model. After induction of severe lung injury by repeated saline lung lavage, 18 adult white Japanese rabbits were randomly assigned to 3 groups: Group I, CNEP (extra thoracic negative pressure, $-10 \mathrm{cmH}_{2} \mathrm{O}$ ) with HFO (mean airway pressure (MAP), $10 \mathrm{cmH}_{2} \mathrm{O}$ ); Group 2, HFO (MAP, $10 \mathrm{cmH}_{2} \mathrm{O}$ ); and Group 3, HFO (MAP, $15 \mathrm{cmH}_{2} \mathrm{O}$ ). Physiological and blood gas data were compared among groups using analysis of variance.

Results: Group I showed significantly higher oxygenation than Group 2, and the same oxygenation with significantly higher mean blood pressure compared to Group 3.

Conclusion: Adequate CNEP combined with HFO improves oxygenation with less impact on blood pressure than high-frequency oscillation alone in an animal model of respiratory failure.

\section{Background}

Continuous negative extrathoracic pressure (CNEP) applied around the chest was been shown to be efficacious in the treatment of respiratory failure in infants [15]. CNEP can produce increased functional residual capacity and may lead to increased cardiac output by increasing cerebral venous return and decreasing pulmo- nary vascular resistance $[6,7]$. However, wide use of this technique has not been seen in the neonatal field, as creating negative pressure around the fragile chest wall is difficult in neonates.

High-frequency oscillation (HFO) has been shown to prevent both acute and chronic lung injury in neonatal man- 
agement. Specifically, HFO has been shown to reduce the incidence of chronic lung disease in very low birth weight infants [8-10]. Studies of surfactant deficiency in animal models have demonstrated that volume recruitment is one of the important lung protective strategies during HFO $[11,12]$.

In the present study, we hypothesized that CNEP combined with HFO would offer greater improvements in oxygenation than HFO alone in a rabbit model of surfactant depletion.

\section{Materials and methods Animal model}

The study protocol was approved by the Institutional Animal Care and Committee of Nagano Children's Hospital, Nagano, Japan. Eighteen adult white Japanese rabbits weighing 2.0-2.5 kg were used for this study. All animals were premedicated by intramuscular administration of ketamine $(10 \mathrm{ml} / \mathrm{kg})$ and xyladine $(5 \mathrm{mg} / \mathrm{kg})$. The peripheral ear vein was cannulated using a 24-gauge angiocatheter for intravenous anesthesia and infusion of medication. Animals were placed in a supine position during the entire study period. A 3.5-Fr endotracheal tube without cuff (Mallinckrodt, St. Louis, Missouri, USA) was inserted into the trachea and tied to prevent gas leak. The carotid artery was cannulated using a 22-gauge angiocatheter and connected to a blood pressure monitor (Polygraph System; Nihon Koden, Tokyo, Japan) to monitor arterial blood pressure and heart rate, and to obtain arterial blood samples for blood gas analysis. Anesthesia was provided by continuous intravenous infusion of ketamine $(5 \mathrm{mg} / \mathrm{kg} /$ h) and paralysis was maintained using pancuronium $(0.1$ $\mathrm{mg} / \mathrm{kg} / \mathrm{h}$ ). Mechanical ventilation was performed using a time-cycled, pressure-limited ventilator (Humming II; Metran, Saitama, Japan). Animals were administered 10\% glucose in $0.45 \%$ saline solution at $3 \mathrm{ml} / \mathrm{kg} / \mathrm{h}$ throughout the study period without any colloid or catecholamine.

\section{Measurements}

Oxygen saturation, heart rate and blood pressure were monitored continuously using a pulse oximeter (Nihon Koden, Tokyo, Japan). Tidal volume (Vt) was measured intermittently using a low-dead space hot-wire pneumotachograph (Aivision Laminar Flow Meter LFM-317; Metabo, Lausanne, Switzerland). Arterial blood gas samples were analyzed intermittently $(0,30,60,90$ and 120 min). Blood pressure, heart rate and ventilator settings were recorded before and after lung injury and at 30-min intervals during the 120-min study period.

\section{Experimental protocol}

After obtaining baseline measurements, acute respiratory failure was induced by repeated lung lavage with aliquots of $30 \mathrm{ml} / \mathrm{kg}$ of warmed normal saline. Lavage was consid- ered adequate if $\mathrm{PaO}_{2}$ was $<80 \mathrm{mmHg}$ by $15 \mathrm{~min}$ after last lavage with the following ventilator settings: $\mathrm{FiO}_{2} 1.0$ at a respiratory rate of 30 breaths/min with positive end expiratory pressure (PEEP) of $5 \mathrm{cmH}_{2} \mathrm{O}$; peak inspiratory pressure (PIP) to maintain $\mathrm{Vt}$ of $15 \mathrm{ml} / \mathrm{kg}$; and inspiratory time of $1.0 \mathrm{~s}$. To induce severe and stable lung injury, animals were ventilated mechanically for $60 \mathrm{~min}$ at the above settings.

To determine the adequate CNEP level combined with HFO (mean airway pressure (MAP), $10 \mathrm{cmH}_{2} \mathrm{O}$ ) in our study, we conducted a preliminary examination of oxygenation at each CNEP level (extra thoracic negative pressures: $-5 \mathrm{cmH}_{2} \mathrm{O} ;-10 \mathrm{cmH}_{2} \mathrm{O}$; and $-15 \mathrm{cmH}_{2} \mathrm{O}$ ) combined with HFO. CNEP $\left(-5 \mathrm{cmH}_{2} \mathrm{O}\right)$ combined with HFO showed no change in oxygenation compared with $\mathrm{HFO}$ alone. CNEP combined with HFO (MAP, $10 \mathrm{cmH}_{2} \mathrm{O}$ ) showed the same oxygenation level at $-10 \mathrm{cmH}_{2} \mathrm{O}$ or -15 $\mathrm{cmH}_{2} \mathrm{O}$.

From these preliminary results, we decided to use CNEP ($10 \mathrm{cmH}_{2} \mathrm{O}$ ) in our experimental protocol. Animals were randomly allocated to 3 therapy groups. Group 1 used CNEP (extra thoracic negative pressure $-10 \mathrm{cmH}_{2} \mathrm{O}$ ) with HFO (MAP $10 \mathrm{cmH}_{2} \mathrm{O}$ ). CNEP (RTX; Medivent, London, UK) settings were as follows: CNEP at $-10 \mathrm{cmH}_{2} \mathrm{O}$ and neonatal size selected for the cuirass. HFO settings were as follows: MAP at $10 \mathrm{cmH}_{2} \mathrm{O}$ and pressure amplitude adjusted to maintain $\mathrm{PaCO}_{2}$ between 35 and $55 \mathrm{mmHg}$ at a frequency of $15 \mathrm{~Hz}$. Group 2 used HFO alone at MAP 10 $\mathrm{cmH}_{2} \mathrm{O}$, and Group 3 used HFO alone at MAP $15 \mathrm{cmH}_{2} \mathrm{O}$.

\section{Statistical Analysis}

All results are expressed as mean \pm standard deviation, and were compared using analysis of variance (ANOVA) for repeated measures with Scheffé's test. Values of $\mathrm{p}<$ 0.05 were considered statistically significant.

\section{Results}

Baseline and post-injury data were similar in all 3 groups. Changes in $\mathrm{PaO}_{2}$ over time are shown in Figure 1. In Group $1\left(-10 \mathrm{cmH}_{2} \mathrm{O}\right.$ CNEP with HFO; MAP $\left.10 \mathrm{cmH}_{2} \mathrm{O}\right)$, $\mathrm{PaO}_{2}$ increased after starting CNEP and was significantly higher than in Group 2 (HFO; MAP, $\left.15 \mathrm{cmH}_{2} \mathrm{O}\right)(\mathrm{p}<$ 0.05 ). Group 3 (HFO; MAP $15 \mathrm{cmH}_{2} \mathrm{O}$ ) displayed similar $\mathrm{PaO}_{2}$ to Group 1. Changes in MAP during the observation period are shown in Figure 2. Mean arterial pressure was significantly lower in Group 3 than in Group $1(\mathrm{p}<0.05)$ throughout the experimental period.

\section{Discussion}

PEEP is generally accepted to increase transpulmonary pressure, thus increasing lung volume and reopening some previously collapsed lung units. An alternative approach to increasing transpulmonary pressure, and 
Figure 1

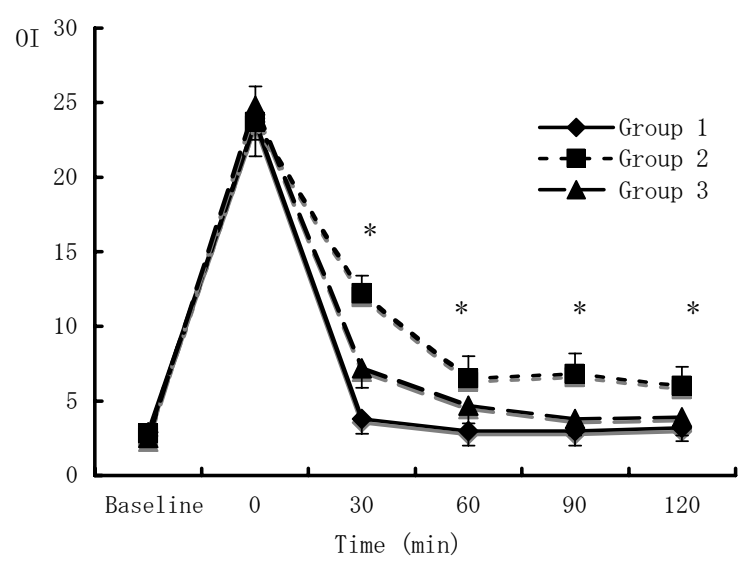

Figure I

Changes in oxygen index (OI) in experiments. (Diamond) Group I: CNEP (-IO $\mathrm{cmH}_{2} \mathrm{O}$ ) with low-MAP (I0 $\mathrm{cmH}_{2} \mathrm{O}$ ) HFO. (Circle) Group 2: Low-MAP $\left(\mathrm{IO} \mathrm{cmH}_{2} \mathrm{O}\right)$ HFO. (Square) Group 3: High-MAP $\left(I 5 \mathrm{cmH}_{2} \mathrm{O}\right)$ HFO. ${ }^{*} \mathrm{p}<$ 0.05 Groups I, 3 vs. Group 2.

thus lung volume, is represented by application of negative pressure around the chest. Randomized trials to assess the benefits of CNEP and standard care in preterm infants have been described [3]. Telford et al. reported long-term

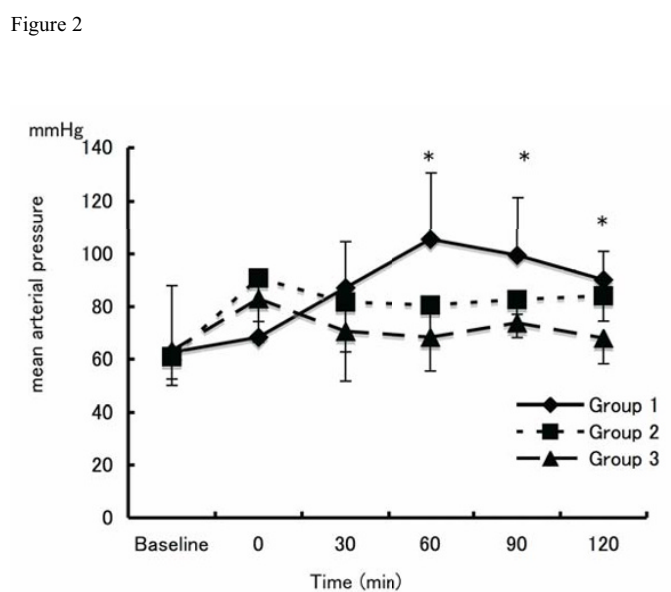

Figure 2

Changes in mean arterial pressure. (Diamond) Group I: CNEP $\left(-10 \mathrm{cmH}_{2} \mathrm{O}\right)$ with low-MAP $\left(10 \mathrm{cmH}_{2} \mathrm{O}\right) \mathrm{HFO}$. (Circle) Group 2: Low-MAP ( $\left.\mathrm{IO} \mathrm{cmH}_{2} \mathrm{O}\right)$ HFO. (Square) Group 3: High-MAP $\left(15 \mathrm{cmH}_{2} \mathrm{O}\right) \mathrm{HFO}$. ${ }^{*} \mathrm{p}<0.05$ Group I vs. Group 3. outcomes after neonatal CNEP [5]. They showed that death or sever disability was equally distributed between CNEP group and standard treatment group. Full IQ did not differ significantly between groups, but mean performance IQ was higher in the CNEP group. CNEP was also useful in more mature infants with other types of respiratory failure $[1,2]$. In the treatment of acute lung injury, application of CNEP increased transpulmonary pressure, thus achieving improved lung function similar to that obtained with PEEP. As opposed to PEEP, which increases intrathoracic pressure, CNEP increases transpulmonary pressure by decreasing intrathoracic pressure, rather than by increasing airway pressure. CNEP has favorable effects on permeability and hydrostatic pulmonary edema $[6,7]$. In a sheep model inoculated with Pseudomonas bacteria, CNEP decreased hydrostatic filtration pressure and lung lymph flow [13]. In dogs with pulmonary edema induced by oleic acid, CNEP increased extravascular lung water volume, but did not change central blood volume [14]. Shekerdemian et al. reported that CNEP improved cardiac output in children after cardiac surgery [15-17]. However, CNEP has been not widely used in neonatal intensive care unit, as extrathoracic devices are not easy to fix to the chest wall of neonates, and maintaining constant extrathoracic negative pressure is difficult.

HFO is a gentler mechanical ventilation approach with very low tidal volume and fixed mean airway pressure, which decreases the pressure swing in the peripheral airways and alveoli, and may result in a reduction of lung injury. HFO started after birth can prevent the development of chronic lung disease in very low birth weight infants at high risk for respiratory distress syndrome [810]. Sustained increases in MAP could induce rapid, large increases in $\mathrm{PaO}_{2}$ in the lungs, exhibiting some hysteresis in pressure/volume relationships [11,12]. However, higher MAP utilized during HFO could conceivably impede venous return and lead to hypotension. In neonates, this might result in intracranial hemorrhage [18].

Although the present study was limited by a lack of direct measurement of transpleural pressure and cardiac output, we showed that adequate CNEP combined with HFO results in the same level of oxygenation and significantly higher mean blood pressure compared with high MAP $\mathrm{HFO}$-only groups. In neonate, high MAP HFO easily affect on circulation and need volume expander or catecholamine to keep adequate blood pressure. Although, further experiments are needed to develop a more comfortable and useful cuirass that can be adjusted to individual neonatal chest size for long-term use in human neonate, we can try this ventilator combination in neonate who has severe respiratory and circulatory failure. Based on these experimental data, we speculate that ade- 
quate CNEP might play a role as a continuous volume recruitment maneuver during $\mathrm{HFO}$ or change in pulmonary blood flow or increases in cardiac output. Some articles have described comparative evaluations of hemodynamic effects for CNEP and positive end-expiratory pressure [19-22], no studies appear to have shown the combined effects of CNEP and HFO on oxygenation in an animal model of lung injury. We hope to look at adequate circulation in CNEP with HFO in further experiments.

We conclude that adequate CNEP combined with HFO improves oxygenation with less impact on blood pressure than HFO alone in an animal model of surfactant depletion.

\section{Acknowledgements}

This study was funded by a grant for scientific research from the Ministry of Health and Welfare of Japan.

\section{References}

I. Samuels MP, Southall DP: Negative extrathoracic pressure in treatment of respiratory failure in infants and young children. $B M J \mid$ 1989, 299: | 253-| 257.

2. Hartmann H, Jawad MH, Noyes J, Samuels MP, Southall D: Negative extrathoracic pressure ventilation in central hypoventilation syndrome. Arch Dis Child 1994, 70:418-423.

3. Samuels MP, Raine J, Wright T, Alexander JA, Lockyer K, Spencer SA, Brookfield DS, Modi N, Harvey D, Bose C, Southall DP: Continuous negative extrathoracic pressure in neonatal respiratory failure. Pediatrics 1996, 98: II54-1160.

4. Klonin H, Campbell C, Hawthorn J, Southall DP, Samuels MP: Negative extrathoracic pressure in infants with cystic fibrosis and respiratory failure. Pediatr Pulmonol 2000, 30:260-264.

5. Telford K, Waters L, Vyas H, Manktelow BN, Draper ES, Marlow N: Outcome after neonatal continuous negative-pressure ventilation: follow-up assessment. Lancet 2006, 367:1080-1085.

6. Skaburskis M, Helal R, Zidulka A: Hemodynamic effects of external continuous negative pressure ventilation compared with those of continuous positive pressure ventilation in dogs with acute lung injury. Am Rev Respir Dis 1987, I36:886-89|

7. Skaburskis M, Michel RP, Gatensby A, Zidulka A: Effect of negativepressure ventilation on lung water in permeability pulmonary edema. I Appl Physiol 1989, 66:2223-2230.

8. Gerstmann DR, Minton SD, Stoddard RA, Meredith KS, Monaco F, Bertrand JM, Battisti O, Langhendries JP, Francois A, Clark RH: The Provo multicenter early high-frequency oscillatory ventilation trial: improved pulmonary and clinical outcome in respiratory distress syndrome. Pediatrics 1996, 98: 1044-1057.

9. Cools F, Offringa M: Meta-analysis of elective high frequency ventilation in preterm infants with respiratory distress syndrome. Arch Dis Child Fetal Neonatal Ed 1999, 80:FI5-20.

10. Courtney SE, Durand DJ, Asselin JM, Hudak ML, Aschner JL, Shoemaker CT: Neonatal Ventilation Study Group. High-frequency oscillatory ventilation versus conventional mechanical ventilation for very-low-birth-weight infants. $N$ Engl J Med 2002, 347:643-652.

11. Kolton M, Cattran CB, Kent G, Volgyesi G, Froese AB, Bryan AC: Oxygenation during high-frequency ventilation compared with conventional mechanical ventilation in two models of lung injury. Anesth Analg 1982, 61:323-332.

12. Byford $L J$, Finkler $J H$, Froese $A B$ : Lung volume recruitment during high-frequency oscillation in atelectasis-prone rabbits. J Appl Physiol 1988, 64:1607-16|4.

13. Krumpe P, Gorin AB: Continuous negative external chest pressure decreases transvascular lung water transport in sheep after Pseudomonas bacteremia. J Clin Invest 1981, 67:264-273.

14. Kudoh I, Andoh T, Doi H, Kaneko K, Okutsu Y, Okumura F: Continuous negative extrathoracic pressure ventilation, lung water volume, and central blood volume. Studies in dogs with pulmonary edema induced by oleic acid. Chest 1992, 10 1:530-533.

15. Shekerdemian LS, Bush A, Lincoln C, Shore DF, Petros AJ, Redington AN: Cardiopulmonary interactions in healthy children and children after simple cardiac surgery: the effects of positive and negative pressure ventilation. Heart 1997, 78:587-593.

16. Shekerdemian LS, Bush A, Shore DF, Lincoln C, Redington AN: Cardiopulmonary interactions after Fontan operations: augmentation of cardiac output using negative pressure ventilation. Circulation 1997, 96:3934-3942.

17. Shekerdemian LS, Shore DF, Lincoln C, Bush A, Redington AN: Negative-pressure ventilation improves cardiac output after right heart surgery. Circulation 1996, 94:1149-55.

18. The HIFI Study Group: High-frequency oscillatory ventilation compared with conventional mechanical ventilation in the treatment of respiratory failure in preterm infants. $N \mathrm{Eng} / \mathrm{J}$ Med 1989, 320:88-93.

19. Easa D, Mundie TG, Finn KC, Hashiro G, Balaraman V: Continuous negative extrathoracic pressure versus positive end-expiratory pressure in piglets after saline lung lavage. Pediatr Pulmonol 1994, 17:161-168.

20. Mundie TG, Finn K, Balaraman V, Sood S, Easa D: Continuous negative extrathoracic pressure and positive end-expiratory pressure. A comparative study in Escherichia coli endotoxintreated neonatal piglets. Chest 1995, 107:249-255.

2I. Torelli L, Zoccali G, Casarin M, Dalla Zuanna F, Lieta E, Conti G: Comparative evaluation of the haemodynamic effects of continuous negative external pressure (CNEP) and positive end-expiratory pressure (PEEP) in mechanically ventilated trauma patients. Intensive Care Med 1995, 21:67-70.

22. Borelli M, Benini A, Denkewitz T, Acciaro C, Foti G, Pesenti A Effects of continuous negative extrathoracic pressure versus positive end-expiratory pressure in acute lung injury patients. Crit Care Med 1998, 26:1025-1031.

Publish with Biomed Central and every scientist can read your work free of charge

"BioMed Central will be the most significant development for disseminating the results of biomedical research in our lifetime. "

Sir Paul Nurse, Cancer Research UK

Your research papers will be:

- available free of charge to the entire biomedical community

- peer reviewed and published immediately upon acceptance

- cited in PubMed and archived on PubMed Central

- yours - you keep the copyright 